\title{
Climatologically based warning system against meteorological hazards and weather extremes: the example for Poland
}

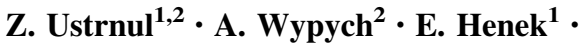 \\ M. Maciejewski ${ }^{1} \cdot$ B. Bochenek ${ }^{1}$
}

Received: 28 July 2014 / Accepted: 26 February 2015/Published online: 13 March 2015

(C) The Author(s) 2015. This article is published with open access at Springerlink.com

\begin{abstract}
This work presents a detailed scientific concept of an operational warning system concerning weather hazards, which is a component of the IT System for Country's Protection against extreme hazards currently under development in Poland. The system displays eight weather hazards that prevail in Poland (air temperature extremes, heavy rainfall, strong wind, intensive snowfall, fog, glaze, rime, and thunderstorms with hail), which are presented on the maps. The information will also be made available to the public in the form of warnings sent automatically via the Internet or text messages. The weather hazard maps consist of two highly complementary components. The first contains maps of areas vulnerable to the hazards' occurrence (climatological maps). These are based on observational and measurement data covering the period of 1951/1966-2010. The second component consists of operational maps based on current weather conditions, including primarily predictive data provided by the mesoscale numerical weather prediction model ALADIN (warning maps). The climatological information has been applied to the operational maps for several extremes not directly predicted by the ALADIN model.
\end{abstract}

Keywords Meteorological hazards - Weather extremes - Warning system - Climatic maps · Poland

$\triangle$ A. Wypych

agnieszka.wypych@uj.edu.pl

Z. Ustrnul

zbigniew.ustrnul@imgw.pl

1 Institute of Meteorology and Water Management, National Research Institute, ul. Podlesna 61, 01-673 Warsaw, Poland

2 Institute of Geography and Spatial Management, Jagiellonian University, ul. Gronostajowa 7, 30-387 Kraków, Poland 


\section{Introduction}

Natural disasters, primarily weather-related natural disasters, play a prominent role in the functioning of the environment, society, and economy. They cause economic losses as well as human suffering and casualties. Some of them, such as hurricanes, thunderstorms, and hailstorms, are the direct causes of these losses, and the intensity level alone is a danger. Less-severe but long-lasting phenomena (high or low temperature) may also have catastrophic consequences, or they can be a trigger for other threats, for example heavy rainfalls - the direct cause of floods. The third group of weather-related disasters consists of those that occur as a result of the accumulation of specific weather conditions intensified by local characteristics of the environment (rime, glaze, and fog).

For this reason, there is a major effort, nationally and internationally, to reduce the negative consequences of such disasters. The first actions taken to achieve this are improving scientific understanding of the range of natural hazards that can occur, delimiting regions that are particularly liable to their occurrences, and providing improved forecasting. Within the implementation of the WMO Disaster Risk Reduction Programme (WMO 2014), early-warning systems (EWS) (WMO 2005, 2010) are being developed in a growing number of countries. The systems both include a traditional research-based approach and at the same time introduce plain-language descriptions that are clearly understood by the public (user-centred interfaces).

On account of its transitional location in Europe as well as differentiation of relief, Poland is exposed to particular weather extremes. Some of them, for example intense precipitation, are the direct causes of flooding, which in Central Europe is widely regarded as the most destructive natural disaster (Kundzewicz 2012). Others, although occurring sporadically or seasonally, generally lead to smaller losses, yet sometimes they can also be severe (e.g. freezes, rime, glaze, and hailstorms). Hopefully, despite the often expressed view of the increase in the number of weather extremes due to progressive climate change, the contemporary research on climate change (Brönnimann et al. 2008; IPCC 2001; IPCC 2013) does not confirm that the frequency of weather hazards is increasing. It has been proved only for temperature extremes, whereas there is limited evidence of changes in extremes associated with other climate variables (including extreme winds and small-scale severe weather phenomena such as thunderstorms and hail).

In Poland, the system for meteorological protection functions as a part of the National Hydrological and Meteorological Service, which cooperates with emergency services and national government bodies. There is, however, no operational system for rapid transmission of current information on potential weather threats available to all citizens. Similar systems have already been launched in, among other countries, France, Germany, Japan, and the USA (Golnaraghi (2012). Other noteworthy systems include the regional EWS (e.g. Gaztelumendi et al. 2012; Tang et al. 2012), systems devoted to a particular phenomenon (e.g. Lakshmanan et al. 2007; Stensrud et al. 2013) or issues (e.g. Ebi and Schmier 2005) as well as those systems operating within the range of water-related hazards in some European countries (Alfieri et al. 2012).

In response to existing problems, there has been an initiative aimed at consolidating information about hazards and placing this information in a professional IT system using an integrated database and modern module for communicating. The IT System for Country's Protection System against extreme hazards (Polish acronym ISOK) is designed to solve or minimize a number of problems related to the issue of crisis management in Poland with special attention to be paid to flood risks, but without diminishing the 
significance of other extreme hazards. For the realization of the concept of the abovementioned Disaster Risk Reduction Programme, meteorological hazard maps were implemented as a part of the system. Their main aim is to present select weather phenomena in Poland, by relying on a detailed climatological analysis and then displaying the information on their forecast occurrences. The system was developed using state-of-the-art information technology and geographical information system solutions.

The aim of this study is to present the warning system with respect to meteorological hazards. The work discusses the scientific and climatological basis, methodological assumptions, and solutions that were employed in the presentation of particular meteorological hazards.

\section{Maps of meteorological hazards and extremes}

Of all the weather phenomena occurring in Poland, eight weather elements and phenomena have been selected for further consideration and presentation in the system. Their choice was first preceded by the evaluation of the incidence of meteorological phenomena and their intensity representing a potential hazard in Poland. Current registration of atmospheric phenomena is carried out at the synoptic and climatological stations, whereby detailed statistics are conducted only for selected events (Table 1). The most likely to occur in Poland (defined on the basis of a multi-year data analysis from 1966 to 2010) are characterized by strong wind $(v>10 \mathrm{~m} / \mathrm{s})$ storms, and above all, fog, which is characterized by a doubly higher incidence than other phenomena (Table 1).

In accordance with European standards (within the EUMETNET-Network of European Meteorological Services), the National Public Weather Service (NWS) of Poland (Institute of Meteorology and Water Management-National Research Institute, IMWMNRI) provides important severe weather information, continually refining the criteria for

Table 1 Particular weather phenomena occurrence or forecast as hazardous in Poland (explanations in the text)

\begin{tabular}{|c|c|c|c|}
\hline \multicolumn{2}{|l|}{ Climatological data } & \multicolumn{2}{|c|}{ NWS (IMWM-NRI) warnings } \\
\hline Weather phenomena & $\begin{array}{l}\text { Frequency of } \\
\text { occurrence (\%) }\end{array}$ & $\begin{array}{l}\text { Frequency of } \\
\text { issues (\%) }\end{array}$ & Weather hazard \\
\hline $\operatorname{Tmax}>30{ }^{\circ} \mathrm{C}$ & 3.4 & 5.5 & Extreme heat \\
\hline $\operatorname{Tmin}<-15{ }^{\circ} \mathrm{C}$ & 5.1 & 3.2 & Extreme cold \\
\hline $\mathrm{RR}>30 \mathrm{~mm}$ & 1.0 & 8.3 & Intensive precipitation \\
\hline Fog & 38.9 & 4.1 & Fog (also rime deposition) \\
\hline Rime & 4.7 & & \\
\hline \multirow[t]{2}{*}{ Blizzard } & 5.7 & 4.0 & Blizzard \\
\hline & & 5.6 & Intensive snowfall \\
\hline Wind $>10 \mathrm{~ms}^{-1}$ & 18.5 & 10.2 & Strong wind \\
\hline Thunderstorm & 17.4 & 36.8 & Thunderstorm (also with hail) \\
\hline Hail & 1.7 & & \\
\hline \multirow[t]{2}{*}{ Glaze } & 3.6 & 12.9 & Icing \\
\hline & & 9.5 & Freezing rain \\
\hline
\end{tabular}


the different degrees of risk so as to take into consideration the specificities of the country and the region. Based on the frequency of issued meteorological warnings (2010-2014), it can be concluded that the most intense phenomena, i.e. those forcing warnings to be issued, are storms and storms with hail and ice (Table 1).

In the last stage, an analysis was conducted of the damage caused by weather phenomena, since phenomena that occur rarely and with devastating force are often times much more dangerous. Fog, for example, occurs frequently throughout the country, though its occurrence is not responsible for far-reaching socio-economic consequences. These, in turn, (apart from the statistics conducted by the Government Safety Centre) are also confirmed by data collected by pan-European institutions (including the European Severe Weather Database and EM-DAT - the International Disaster Database, Guha-Sapir et al. 2015) and are most associated with flooding (property damage) and severe winter conditions, particularly cold waves (casualties) (Table 2).

The analysis of the frequency of hazardous weather phenomena occurrences together with the knowledge of economic and environmental losses allowed for the selection of air temperature extremes, heavy rainfall, strong wind, intensive snowfall, fog, glaze, rime, and thunderstorm with hail as the most hazardous weather phenomena. All of these are defined by the WMO as type 1 hazards (Golnaraghi 2012) and are among the most frequently occurring hazards in Europe (WMO 2010).

The maps of spatial differentiation of the above-mentioned weather hazards and extremes were created on the basis of an improved scientific understanding of the range of natural hazards that occur in Poland and in order to present the regions particularly exposed to extreme weather phenomena from both climatological and forecast perspectives. The maps consist of two separate yet closely inter-related items: climatological maps and warning maps.

\subsection{Climatological maps}

Despite the changing climate (IPCC 2013), the information presenting differences in climatic conditions on the basis of long-term observations is crucial for the analysis and evaluation of weather extremes. In accordance with commonly accepted assumptions, the aim of the climatological maps is to present spatial distribution of chosen weather extremes and phenomena across Poland, highlighting areas of the country vulnerable to a given hazard. The maps show the distribution of extreme values as well as the frequency of their occurrences in order to bring forward their range, magnitude, and intensity. For better understanding of some phenomena, weather conditions favourable for their occurrences

Table 2 Loss quota in Poland (1966-2014) by particular weather disasters (according to EM-DAT)

\begin{tabular}{lllll}
\hline Weather disaster & Occurrence $(\%)$ & Losses $(\%)$ & \\
\cline { 3 - 5 } & & Deaths & People affected & Total damage \\
\hline Extreme temperature & 32.6 & 86.3 & 0.0 & 0.0 \\
Flood & 28.3 & 5.6 & 99.1 & 97.3 \\
Storm & 32.6 & 6.4 & 0.6 & 2.7 \\
Other & 6.5 & 1.7 & 0.3 & 0.0 \\
Total (in real numbers) & 46 events & 2017 people & 372,029 people & $8,152,050,000$ US\$ \\
\hline
\end{tabular}


were also identified and mapped. At the same time, climatological maps are fundamental for the creation of operational maps for chosen hazards (see Sect. 2.2).

The climatological maps were created following an analysis of daily data covering the period of 1951-2010 (regarding data availability for particular elements, the period was shortened to 1966-2010) originating from at least 60 synoptic stations and up to 300 climatological and precipitation stations (depending on the phenomenon analysed). Data from the regional climate model (RegCM) (Elguindi et al. 2011) were also used. Because of the vast variability of the values, especially in the two transitional seasons (spring, fall), in the case of air temperature extremes, heavy rainfalls, and intensive snowfalls, the maps were generated with a more accurate, decadal (10-day-long period) temporal resolution, whereas the other phenomena present monthly or seasonal differentiation.

Due to the varying availability of spatial information, climatological maps were created in two groups distinguished on the basis of the source data. With the application of GIS methods and tools, four methodological approaches were then used within the groups (Fig. 1). The first group consists of maps based on in situ data, utilizing three approaches. The frequency of occurrences in Poland is displayed to distinguish regions that are exceptionally vulnerable to weather extremes and hazards (Fig. 1A). Unfortunately, as some of the phenomena (fog, glaze, rime, and thunderstorm with hail) are extremely local, they could only be depicted with the use of graduated symbol maps, where symbols represent information coming from synoptic stations where the phenomena are permanently observed. Strong winds were approached in the same way, as the measurements of this element are greatly influenced by local conditions.

For temperature extremes, heavy rainfalls, and intensive snowfalls, the frequency of extremes is presented; however, the extremes are distinguished here as values that exceed predefined thresholds (Fig. 1B). The dense station network allowed the visual representation of spatial distribution on contour maps with a properly selected method of interpolation (Dobesch et al. 2007).

The third approach involves the visualization of spatial distribution of maximum and minimum air temperature, precipitation, wind, and snowfall extremes defined by the probabilistic method (e.g. IPCC 2001; Brönnimann et al. 2008; Klein Tank et al. 2009) (Fig. 1C). The probability of $25 \%$ (snowfall only), 10, $5 \%$ (snowfall excluded), and $1 \%$ of occurrence was implemented, which means that a given extreme can occur once per 4 , 10,20 , and 100 cases, respectively.

The second group of maps is created with modelled data (Fig. 1D). They present atmospheric conditions favourable for the occurrences of the chosen phenomena. An analysis concerning the physical processes that take place in the atmosphere which are responsible for the phenomena's occurrences and intensity was undertaken. This was followed by designing algorithms that describe the relationship between weather elements identified as contributing to the processes. Spatial differentiation was achieved with the use of modelled $(\operatorname{Reg} C M)$ data with a resolution of about $20 \mathrm{~km}$. In the case of fog, however, environmental conditions favourable for its occurrence, i.e. topography and land cover, were also taken into consideration.

\subsection{Warning maps}

The aim of the operational maps is to assist with visualizing weather extremes and hazard forecasts. The main input data are derived from the mesometeorological numerical model ALADIN that was selected after close cooperation with the ALADIN Consortium as part of the High Resolution Numerical Weather Prediction Project. The twice-a-day, 

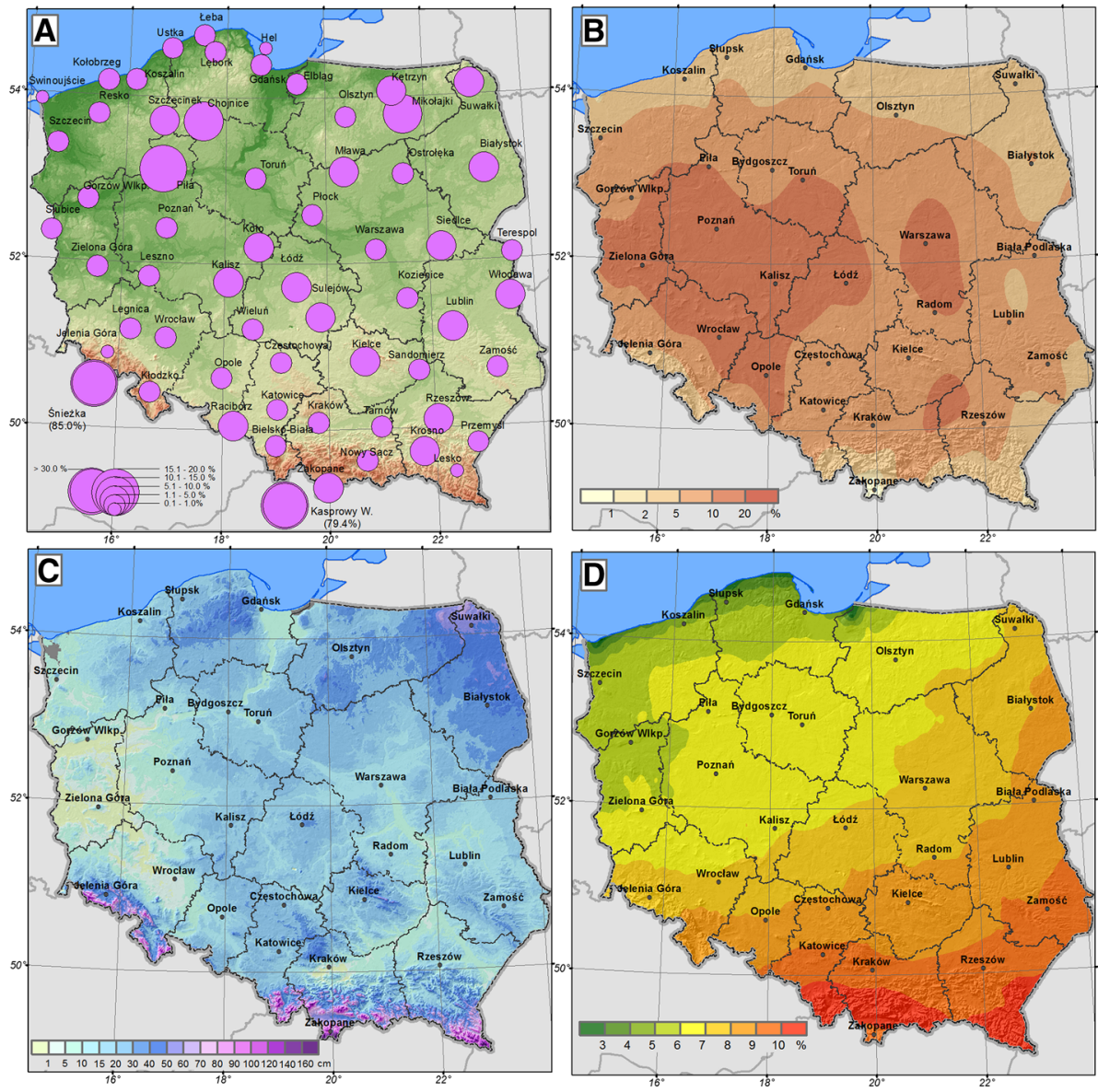

Fig. 1 Types of climatological maps in ISOK system (examples): A Phenomena frequency mapsgraduated symbols method (frequency $(\%)$ of days with observation of rime in February). B Phenomena frequency maps - contour maps (frequency (\%) of days with maximum air temperature $\geq 30{ }^{\circ} \mathrm{C}-\mathrm{July}$, second ten-day period). C Percentile maps (spatial distribution of snow cover depth $(\mathrm{cm})$ with the occurrence probability of $1 \%$-April, first ten-day period). D Favourable conditions frequency maps (annual frequency $(\%)$ of conditions favourable for thunderstorms occurrence)

automatically generated maps will provide forecasts for the nearest 12,24 , and $48 \mathrm{~h}$. The spatial resolution of the model is currently about $7.7 \mathrm{~km}$; however, an effort is being made to improve both the detail (resolution) and quality (physics of the model) of forecasts.

Although the ALADIN model generates information based on over 100 meteorological parameters on various isobaric levels, the occurrence of weather phenomena such as fog, glaze, rime, and thunderstorms with hail are not predicted. Therefore, by using the knowledge gained from the climatological maps and incorporating the ALADIN model, algorithms were designed to forecast conditions that favour the occurrence and sustainability of the phenomena. Consequently, in addition to the standard forecast of main weather elements, the source material for map generation also comes from the results provided by the computation of the algorithms. 
In reference to the specification of described weather extremes and hazards, operational maps will be generated in accordance with three chosen approaches (Fig. 2).

The first approach (Fig. 2-type 1) involves generating warning maps with a climatological background. Threshold values for warning determination are those defining extremes, i.e. an occurrence probability of 10, 5, and 1 percent (Table 3). Such an approach takes into account both regional variability (Lalaurette 2003) of the climate in Poland and temporal differentiation of the extremes. Temperature (maximum and minimum) and precipitation extremes, expressed in percentiles (taken from climatological maps) are distinguished for each 10-day period separately. Similarly, using the criteria that vary according to regions, meteorological warnings are currently generated in several European countries (for chosen elements in Austria, France, Romania, Spain, Portugal, Switzerland, and Italy, among others - to be found on official meteorological services websites), whereas in Serbia, temporal diversity was introduced and the criteria of warnings against heat and freeze depend on which month is considered.

The second approach (Fig. 2-type 2) involves the generation of arbitrary threshold maps. Here the bases are the values generally recognized as threshold values because of the dangers that may occur when they are exceeded, including adverse effects on human health, the environment, and the economy (Klein Tank et al. 2009). Maps of this kind will be provided for temperature extremes, heavy rainfalls, strong winds, and intensive snowfalls (Table 3). User-defined thresholds (depending on particular needs and applications) will be possible to implement for temperature, precipitation, and wind speed as an additional capability of the system (see below).

The third approach (Fig. 2-type 3) uses the previously mentioned defined conditions that favour the occurrences of particular phenomena. The values obtained as the results of

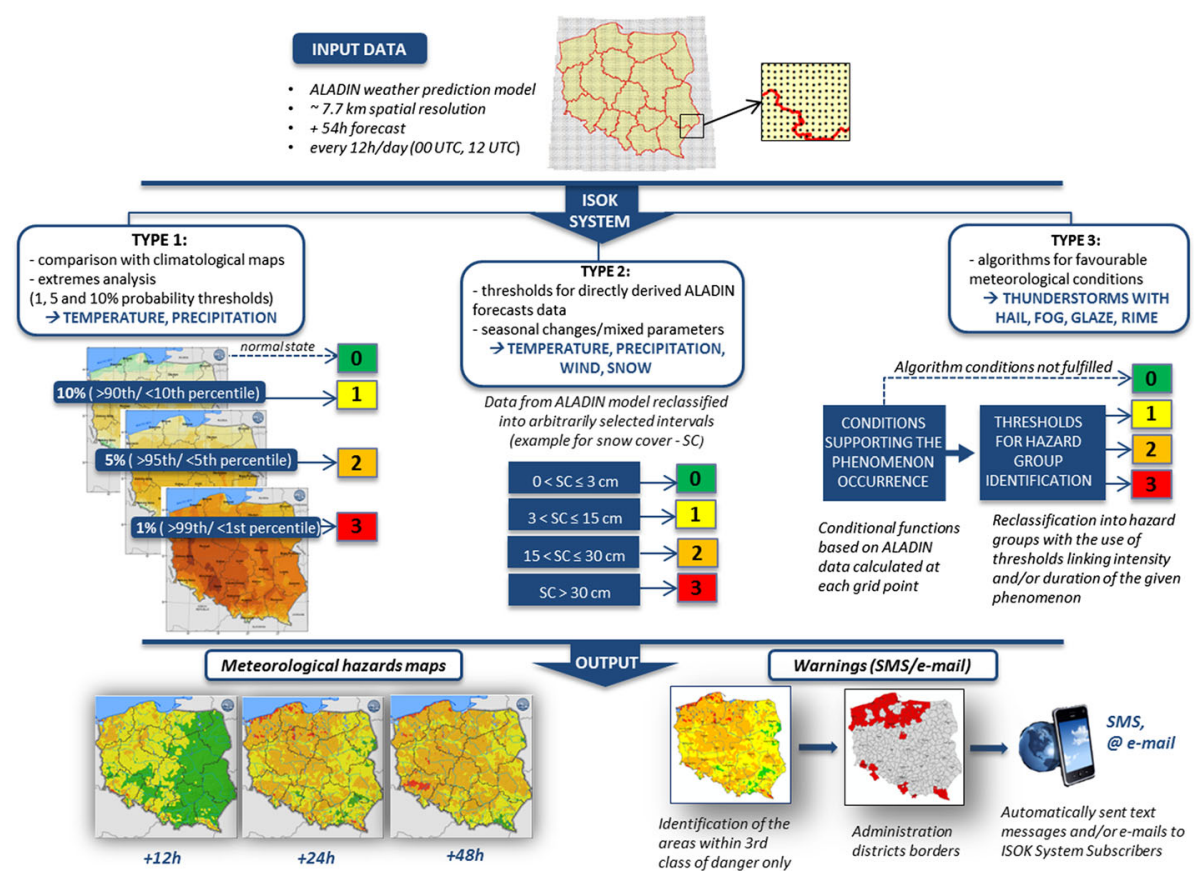

Fig. 2 Workflow of operational maps and warnings creation 


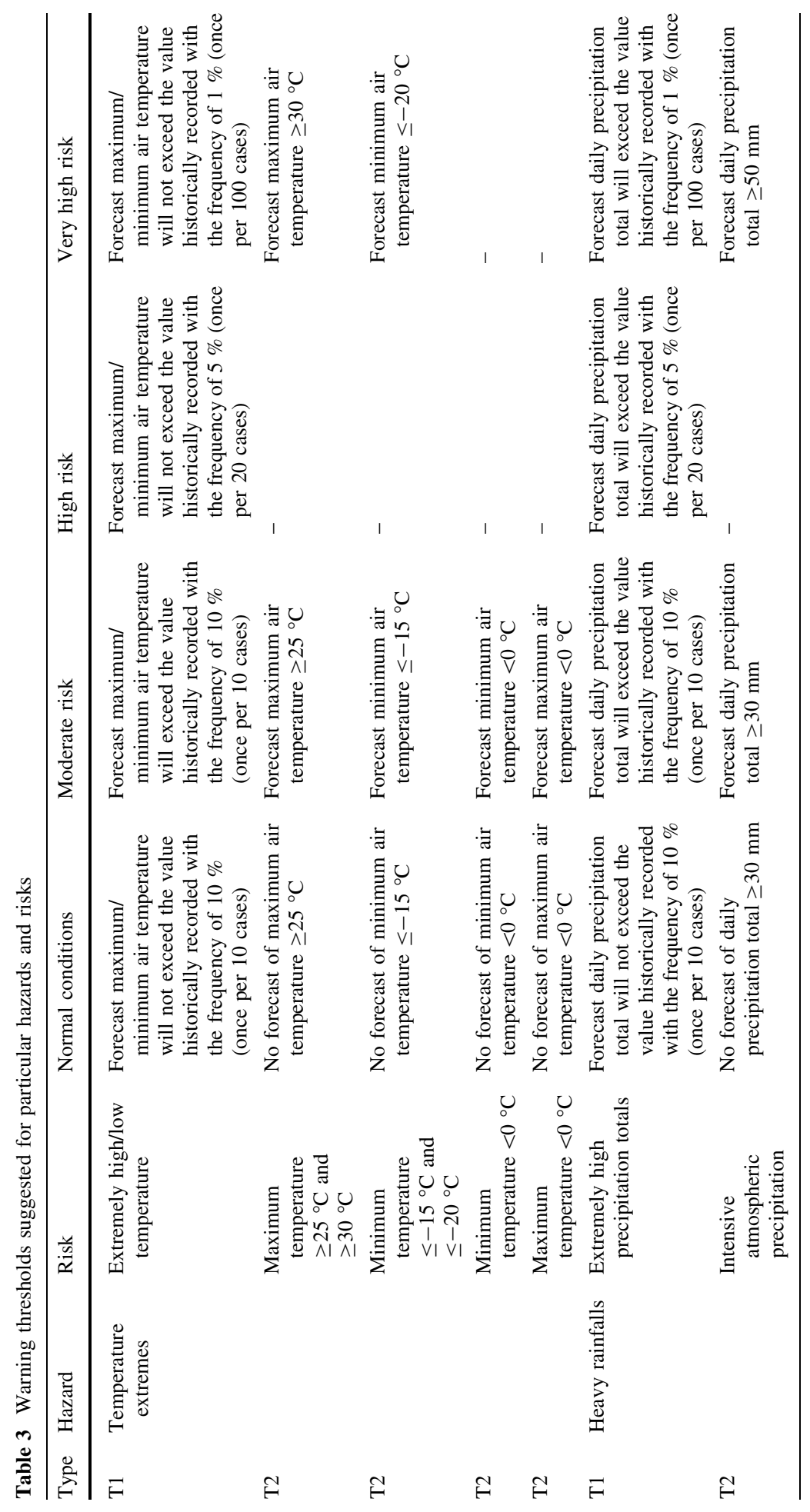




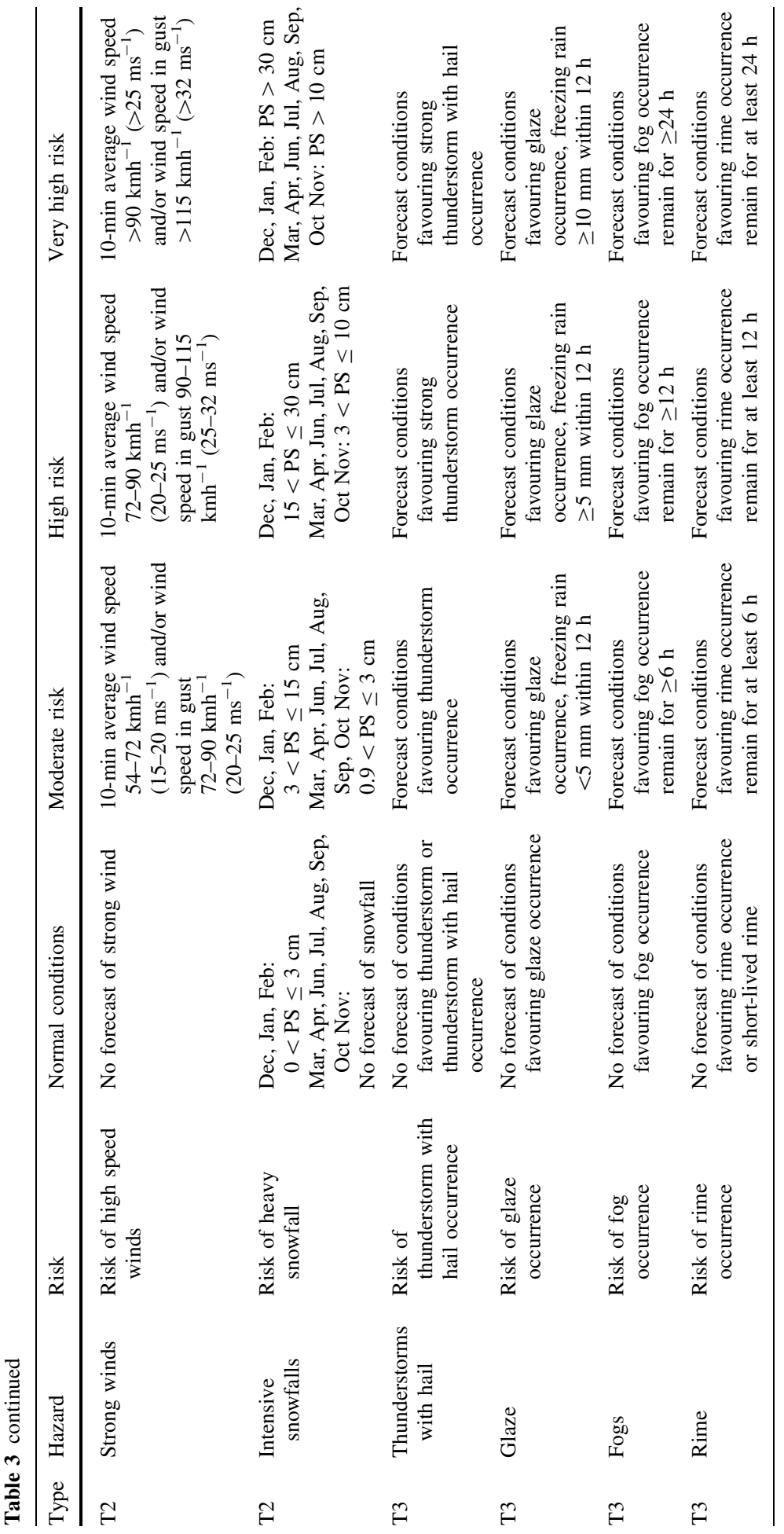


formulated algorithms will be reclassified into groups of hazards on the basis of thresholds combining the duration of favourable conditions and potential intensity of the phenomenon (Table 3).

Reclassified values (by chosen criterion) acquired for particular ALADIN model grid points will then be interpolated in order to achieve full spatial information on the forecasted hazard. The display of hazards in accordance with WMO (2010) standards, applying commonly used colours, allows the recipients fast and accurate perception of information.

Atmospheric processes and phenomena are very dynamic and automatically generated operational maps need constant control and adjustment. Therefore, if necessary, the input of the forecaster from the national meteorological office may be required. Such input will be possible due to other resources available to the forecaster (e.g. information from other mesometeorological models and remote sensing data); however, the knowledge and experience of the person responsible for the assessment are of primary importance.

\section{Meteorological hazard maps in a warning system}

\subsection{Examples of meteorological hazards maps}

The three map sets below present the mechanism of the system's performance and its functionality. All examples come from the testing phase of the system (2013-2014) and point at the essence of the problem of warning representation on automatically generated maps. The maps present warning forecasts generated for the nearest $24 \mathrm{~h}$.

The first example shows the maximum air temperature from 8 August 2013 (Fig. 3). Maps A and D show the spatial distribution of the values predicted by the ALADIN model (A) and the measured maximum air temperature values (D). The others, generated by the system, reflect the level of risk, which is based on an arbitrary threshold (B) and thresholds that are climatologically "weighted", i.e. based on relative thresholds (percentiles) (C). In the last cases, the level of warning depends on overrunning the frequency threshold of maximum temperature value occurrences, where the temperature value is determined for a specified location based on the probability of its occurrence. In other words, Map C takes into consideration the empirical frequency of defined temperature values occurrences, that is, in short, climatological conditions of a given area.

The difference between maps A and D results from the accuracy of the forecast generated by the mesometeorological model, and their analysis seems to be somewhat pointless. In the aforementioned case, the model forecasts the maximum temperature values quite precisely; however, the prognosis indicated a somewhat larger area with a temperature above $35^{\circ} \mathrm{C}$.

In the discussed example, it is worth noting the significant differences on warning maps (B and C) that result directly from the applied method. Example B, based on simple arbitrary thresholds (Fig. 2-type 1), indicates a "very high risk" over a large area of the country. A lower level of risk was forecasted only for the western part of the area. This means that over the greater part of Poland, a temperature above $30^{\circ} \mathrm{C}$ can be expected. Map C, on the other hand, using percentile thresholds to predict the risk (Fig. 2-type 2), shows notably smaller areas that are at risk of the highest level, i.e. southern Poland and a narrow longitudinal lane. There is no highest level of risk in central Poland, in spite of the temperature forecast above $35^{\circ} \mathrm{C}$, which means that such values in this region are more frequent and cannot be regarded as highly extreme. In contrast, the opposite situation is 


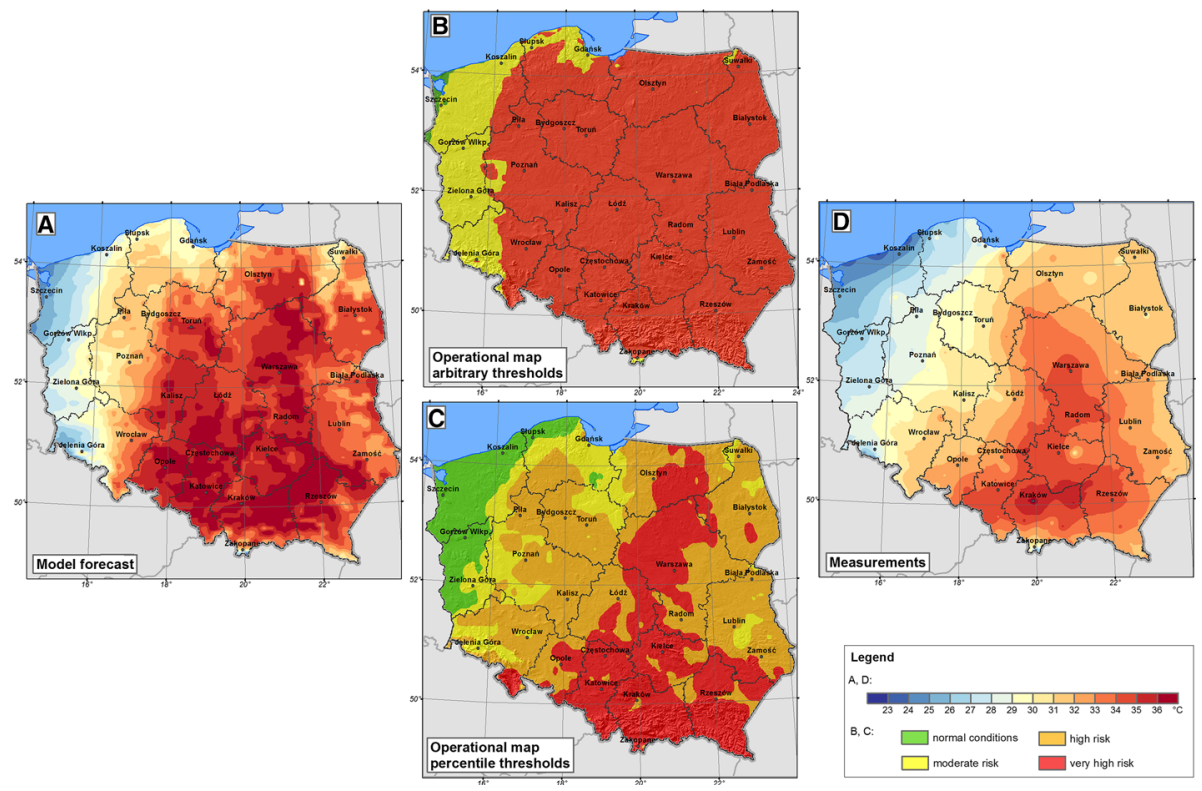

Fig. 3 Spatial distribution of the maximum air temperature-7 August 2013: A map based on forecast data, B warning map — arbitrary thresholds (Tmax $\geq 25^{\circ} \mathrm{C}$ and $\geq 30{ }^{\circ} \mathrm{C}$ ), $\mathbf{C}$ warning map-percentile thresholds, D map based on measured data.

Explanations: A forecast by ALADIN, model run: 00 UTC, valid for period $+6-30 \mathrm{~h}, \boldsymbol{B}$ thresholds described in Table 3, C thresholds (based on 1951-2010) described in Table 3, D map based on 197 measuring points

observed in high mountain areas (above $1800 \mathrm{~m}$ a.s.l.), where temperatures over $25^{\circ} \mathrm{C}$ or even $20{ }^{\circ} \mathrm{C}$ are perceived as extreme. Only in this region are such forecast temperature values regarded as extreme. Thus, the information presents regional characteristics, and it can be concluded as having a mesoscale dimension.

The second example (Fig. 4) presents daily precipitation totals from 15 May, 2014 and is a result of the same solutions that were used in the previous case. Spatial distribution of measured and forecast precipitation totals is very similar, i.e. there is a close resemblance in measured and forecast values (Fig. 4D, A). However, maps B and C show quite significant differences. Map B indicates moderate risk and very high risk over a rather small area limited practically to the Polish Carpathians, where daily totals exceeding $30 \mathrm{~mm}$ and $50 \mathrm{~mm}$ are predicted. Map C, which uses climatological information, shows a noticeably greater area, over a significant south-eastern part of Poland, with high and very high risk. Consequently, it may be regarded that in south-eastern Poland, the forecast precipitation may be potentially more dangerous than it is shown only by the analyses of absolute precipitation totals. The risk results from a lower frequency of such high daily precipitation totals observed over a long-term period.

Finally, example 3 shows how the system forecasts a weather phenomenon (Fig. 5). The methodological approach and presentation of such a phenomenon in the system are consistent with the "type 3" workflow in Fig. 2. Glaze was used as an example, as it is a phenomenon exceptionally difficult to measure and predict and, in addition, not forecast by the ALADIN model. To forecast the phenomena, conditions that favour their occurrences had to be determined through an analysis of atmospheric physical processes. 

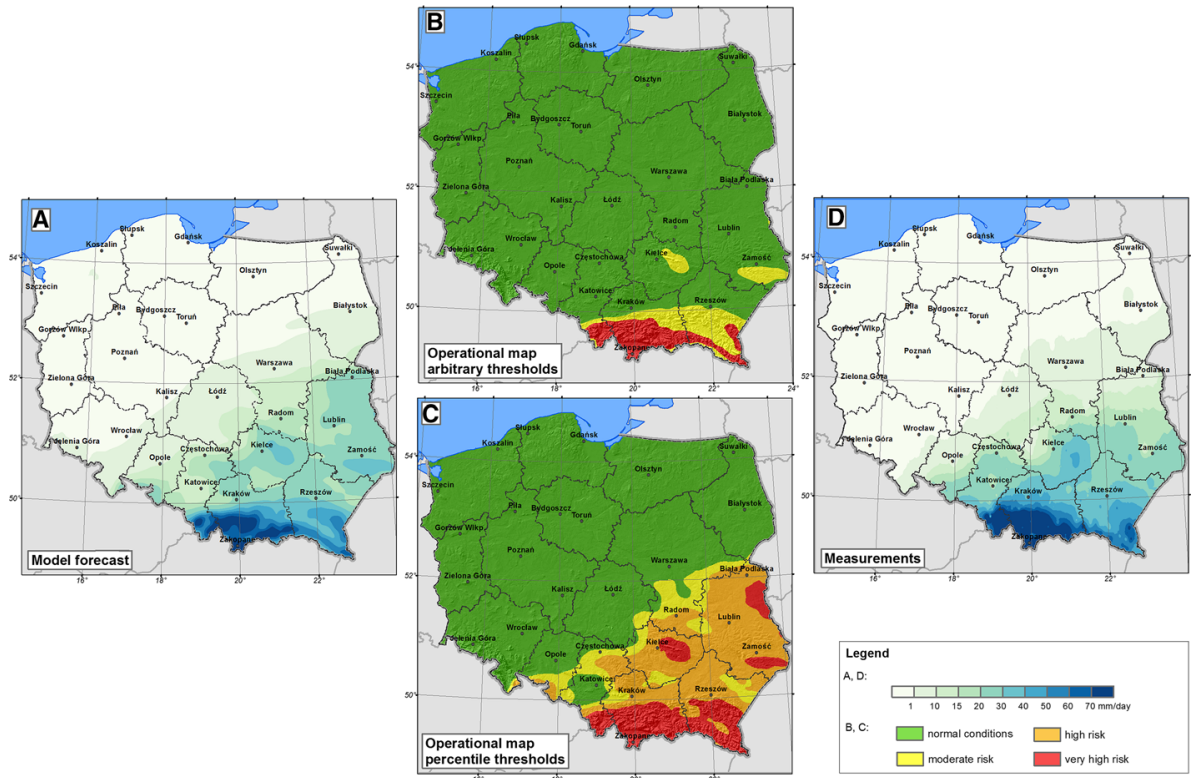

Fig. 4 Spatial distribution of daily precipitation totals-15 May 2014: A map based on forecast data, B warning map-arbitrary thresholds (RR $>30 \mathrm{~mm}$, and $>50 \mathrm{~mm}$ ), C warning map-percentile thresholds, D map based on measured data.

Explanations: A forecast by ALADIN, model run: 00 UTC, valid for period $+6-30 h$, $\boldsymbol{B}$ thresholds described in Table 3, C thresholds (based on 1951-2010) described in Table 3, D map based on 460 measuring points
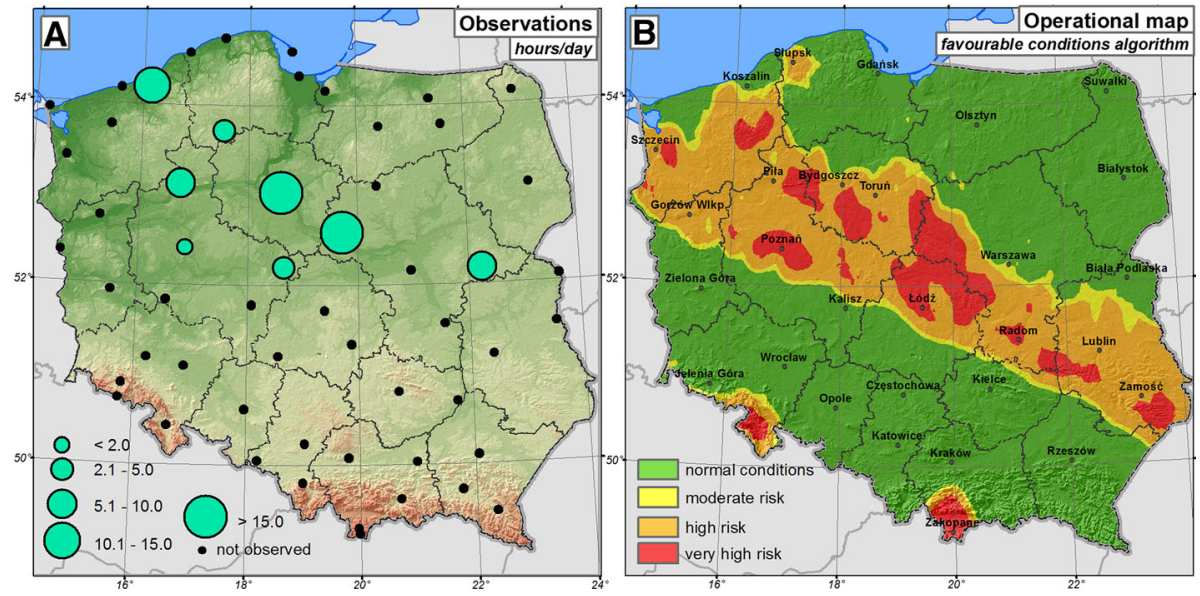

Fig. 5 Spatial distribution of glaze on 18 January 2014: A synoptic station observations_-glaze duration (hours), $\mathbf{B}$ warning map of forecast conditions favourable for glaze occurrence

Map 5A presents the duration of glaze on 18 January 2014 (in hours) observed on stations, whereas Map 5B forecasts conditions that favour the occurrence of this phenomenon. As shown earlier (Fig. 2), the map was generated by the system through an algorithm that describes the relationship among various weather elements. Map 5B must 
be interpreted as information in the area where the risk of glaze is the highest, within the conditions that favour its occurrence.

Summing up, the three examples regarding phenomena of different characteristics are only a general description of the system's functioning. They show that hazards maps can and should be supplemented with climatological information that allows a regional approach to extreme weather conditions, i.e. considering regional climatic diversity. A given value of practically any phenomenon in one region can be regarded as normal or, in other words, common, whereas the same value in another region may already cause a threat. The system, due to a lack of direct forecasts of some dangerous phenomena that are generated in the model, makes it possible to determine areas of their probable occurrences based on the conditions that are favourable for these occurrences.

\subsection{Forecast validation}

The quality of the information generated by the system has constantly been tested. Both the forecast data provided by the model and the accuracy of warning maps are analysed on the basis of measured and observed values. Validation is carried out for all synoptic stations located in Poland. Due to the spatial resolution of the ALADIN forecasts and the regional approach used in meteorological hazard maps, it is implemented in three different spatial perspectives: station grid point, an area of nine grid points (approx. $7.5 \mathrm{~km}$ radius) and an area of 25 grid points (approx. $15 \mathrm{~km}$ radius). Every result undergoes a thorough validation through different parameters estimation using feature-based statistics (Stanski et al. 1989; Casati et al. 2008). The differences between the model and observed values are analysed first, and the mean error of the forecast (bias) is obtained (1).

$$
\operatorname{Bias}=\frac{1}{N} \sum_{i=1}^{N}\left(f_{i}-o_{i}\right)
$$

where $N$-number of stations, $o_{i}$ - value observed at station $i, f_{i}$-model value at grid point located nearest $i$ station (or grid points located within the indicated buffer around $i$ station).

To describe the forecasting accuracy, probability of detection (POD) characteristics (2) and false alarm ratio (FAR) statistic (3) are calculated.

$$
\mathrm{POD}_{i}=\frac{n\left(f_{i} o_{i}\right)}{n\left(o_{i}\right)}
$$

where $n\left(f_{i} o_{i}\right)$ - good forecasts in a given category, $n\left(o_{i}\right)$-all events observed in the same category.

$$
\mathrm{FAR}_{i}=\frac{n\left(f_{i} \neq o_{i}\right)}{n\left(f_{i}\right)}
$$

where $n\left(f_{i} \neq o_{i}\right)$ —false forecasts in a given category, $n\left(f_{i}\right)$-all events forecast in the same category.

In the final stage, for the whole forecast validation, the proportion correct hit rate (PC) (4) is also calculated as the measure of correct forecasts.

$$
\mathrm{PC}=\frac{1}{N} \sum_{i=1}^{N} n\left(f_{i} o_{i}\right)
$$

where $N$-number of stations, $n\left(f_{i} o_{i}\right)$-good forecasts in a given category. 
The analysis is carried out for projections of 12,24 , and $48 \mathrm{~h}$ due to the system of arrangements for both morning (initial time 00 UTC) and afternoon (initial time 12 UTC) model runs.

Validation takes place in two stages. First, the parameter values predicted by the ALADIN model are validated. For the purposes of meteorological hazard maps, these are minimum and maximum air temperature, precipitation, and wind speed. The results of this validation stage are further used for the adaptation of the statistical model.

In the second stage, forecasts generated on the basis of the developed algorithms and ALADIN forecasts are subject to the validation of the system and in both cases are reclassified in the direction of the risk in accordance with the adopted hazard thresholds (Table 3).

The results presented for the analysed period (2013-2014) clearly demonstrate that in the case of the variables directly predicted by the model, reliability is much higher than for the atmospheric phenomena Table 4). For thermal extremes, the probability of detection ranges from over $95 \%\left(\mathrm{Tmin}<0{ }^{\circ} \mathrm{C}\right)$ to about $60 \%\left(\operatorname{Tmax} \geq 25{ }^{\circ} \mathrm{C}\right)$. It is important that extreme cases $\left(\geq 30{ }^{\circ} \mathrm{C} \operatorname{Tmax}\right.$ and $\left.\mathrm{Tmin} \leq-15^{\circ} \mathrm{C}\right)$ have relatively high projection efficiency (PC), but this is due to the fact that they occur sporadically. The effectiveness of the projections also shows situations with a lack of both predicted and observed events. In addition, a low rate of POD for Tmin $\leq-15{ }^{\circ} \mathrm{C}$ confirms that the model is relatively "warm" in the winter. Strong wind is successfully forecast in about $25 \%$ of cases. Although there are a small number of false alarms, the large number of cases missed in fact indicates a barometric field gradient that is weaker than expected. Sporadic occurrence of intensive precipitation in the analysed period unfortunately renders it impossible to assess the functioning of the system in the face of flooding situations in Poland.

The described model imperfections affecting the image of the threat presented in the system are systematically corrected and, as previously mentioned, are used in the process of statistical model adaptation (i.e. systematic correction of the results, taking into account the specific nature of the region, among others).

A much more complicated situation occurs in the case of meteorological phenomena that are forecast as favourable conditions for hazard occurrence (Table 5). Depending on the complexity of the algorithm and parameters used therein, the POD results range from $17 \%$ (rime) to about $40 \%$ (snow). However, the FAR values are decisively high. The results seem to be unsatisfactory; however, it should be remembered that the phenomena are highly variable over time and moreover space. Even over plains, not to mention highlands and mountains, the differences in local conditions of their occurrences can be significant. Observations of glaze, rime, or fog may realistically vary up to tens of metres in the most extreme cases. The forecast presented in the system concerns the conditions conducive to the phenomenon, but not its occurrence. Therefore, the significantly greater number of cases expected (FAR) in this situation should not be confused with an error algorithm.

The current validation of meteorological hazards maps automatically generated in the system, which in specific cases has shown a large discrepancy between forecast and measurement and has also forced the incorporation of on-call forecasters into the process of generating maps. This particularly applies to synoptically difficult cases, where atmospheric circulation changes occur dynamically, much faster than the next forecast is generated by the ALADIN model. Therefore, if necessary, generated maps will bear the current commentary of the forecaster. Such input will be possible due to other resources available to the forecaster (e.g. information from other mesometeorological models and remote sensing data); however, the knowledge and experience of the person responsible for the assessment are of primary importance. 


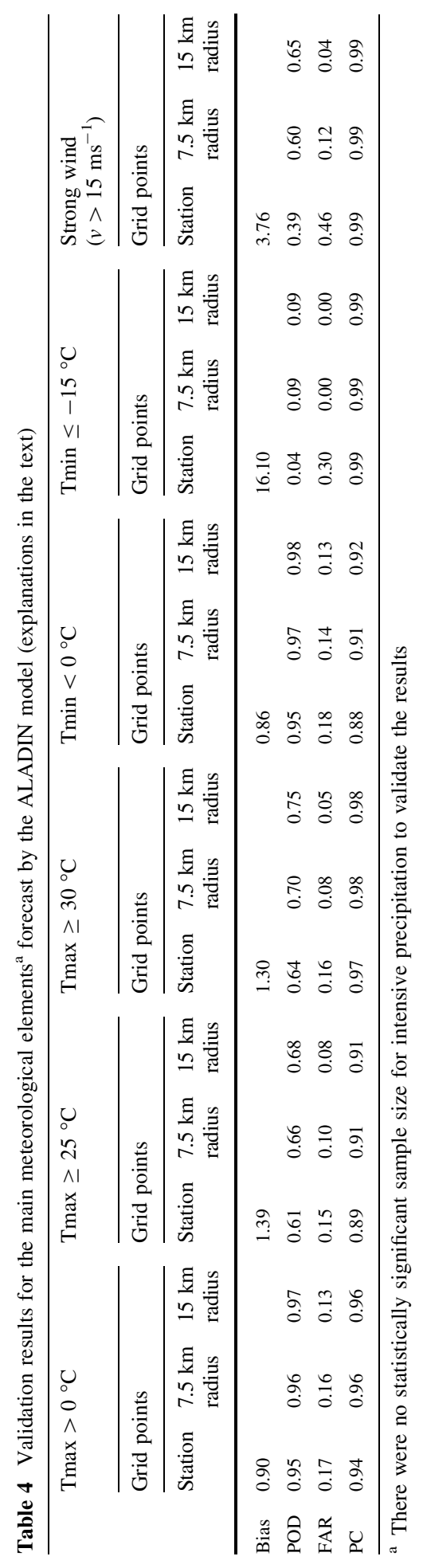




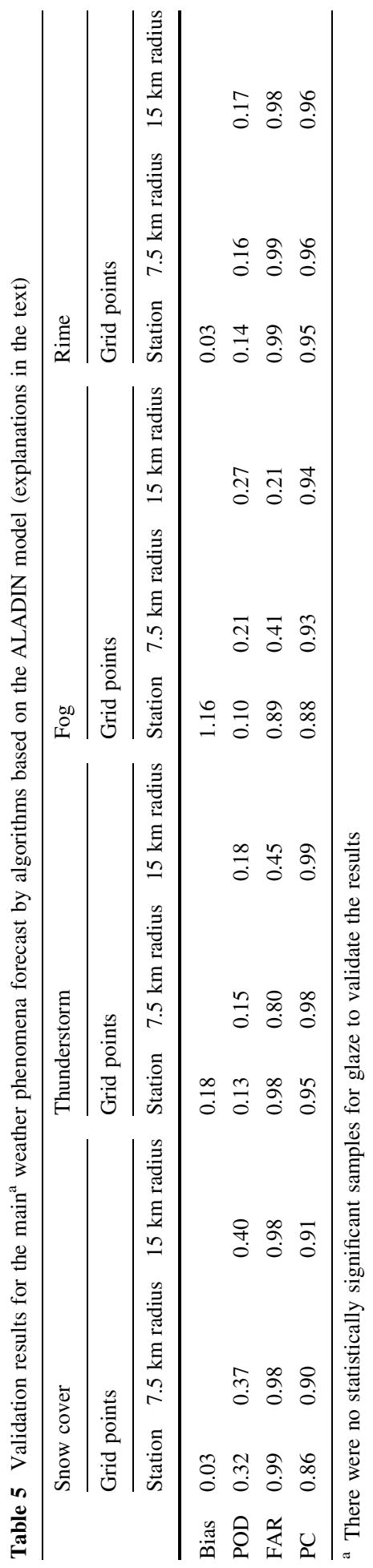




\section{User-oriented functionality of the weather warning system}

Given the impact of meteorological hazards on everyday life, communication, and the economy, it is necessary to provide the public with reliable scientific information about possible threats and to disseminate early warnings regarding the same. To meet these expectations, both climatological and current information have become a part of the warning system that will operate as an environmental database and a compendium of natural disasters in Poland.

Thanks to the extended dynamic GIS workflow and updates every $12 \mathrm{~h}$, a fully operational multi-hazard and early-warning system used to provide information on meteorological hazards will be in place. The main components of the system are the warning maps; however, the map portal is supplied with climatological maps and information explaining the characteristics of presented hazards or phenomena. The information is static, providing a scientific background that allows for better understanding and perception of the information on the potential hazard.

One of the main characteristics of the EWS (Basher 2006) is that it is customized for the user to suit his or her needs. It is crucial that the message is conveyed in a plain and understandable way (there must be certainty that the user recognizes the danger correctly); it must be delivered instantly and directly to subscribers (via e-mails, text messages) (UNISDR 2006; Rogers and Tsirkunov 2011). Therefore, the meteorological hazards maps will be available for everyone without the need to log in, whereas severe weather alerts (for the highest level of warning on operational ISOK maps) as well as user-defined alerts (individually set thresholds for temperature extremes, heavy rainfalls and strong wind) will be generated twice a day and sent as text messages (SMS) and e-mails only for a specific area of interest chosen by the user (Fig. 2).

All of the information appearing in the system will be written with understandable and clear vocabulary since it is the user who has to read the message and interpret the information correctly (Lendholt and Hammitzsch 2012; Mayhorn and McLaughlin 2014). Moreover, to improve the perception of warnings by the public (WMO 2010), additional information will be provided, including a description of the causes of weather hazards, definitions of terminology associated with them, and some historical information about major weather incidents in the country (case studies). As a guide to understanding possible hazards and their consequences, it is planned that e-learning materials and brochures will be accessible and disseminated to the public.

The scientific basis for understanding a phenomenon, rapid access to data, web-GIS portal display, detection of possible hazards in an automatically working process, updating results and messages to provide information to users - all of these will allow ISOK to fulfil the recommendations for designing EWS (Zillman 2003; Golnaraghi (2012); Travis 2013).

\section{Conclusions}

It seems evident that weather hazards maps in ISOK fulfil the requirements of the recently developed EWS methodology existing for weather-related hazards, implemented by National Meteorological Services (NMSs). Climatological maps, based on possibly insightful historical information (obtained thanks to a detailed climatological analysis of phenomena), show characteristics of natural hazards affecting Poland (e.g. intensity, frequency, and probability), and thus help to identify geographical areas and communities 
exposed to weather extremes and hazards. The warning maps will ensure an effective hazard warning system that will provide spatial information on the forecast danger. The warnings will be generated and sent in an efficient and timely manner. Additional information will ensure an understanding of both the nature of the hazards and the warning system itself, as it will contain clear and useful information. The user will have the opportunity to become an informed client, as he or she will be able to set (depending on his or her requirements) personal thresholds for generating warnings.

When trying to forecast a severe weather event, one works within the tail-end regime of statistical distribution. The factors that contribute to both the occurrence of a weather extreme and its magnitude are so numerous that it seems to be nearly impossible to create an intelligent model that would fully automatically generate forecasts and, consequently, warnings against extreme weather events. Since there is a growing expectation that forecasters will be able to warn of incoming weather events earlier, with more emphasis, and greater accuracy, continued research in order to achieve a deeper understanding of the nature of extremes is desirable. With continuing technological development, this will lead to an increasingly better quality of numerical weather prediction. However, it must be stated that due to the physics of the atmospheric processes as well as the temporal and spatial scale of the influence of phenomena, the challenge of hazard forecasting is different. Concerning the local character of some extremes (even strong wind and intensive precipitation), it may be difficult to obtain satisfactory validation results.

The fact that ISOK will be an open system will enable it to accomplish the abovementioned ideas. Its architecture and functionality will allow further improvements and future development, which, in the case of weather hazards maps, is associated with the expansion of forecast weather hazards (with a suitable amount of historical maps), incorporation of other weather prediction models (e.g. COSMO, remote sensing data), as well as offering multi-hazard analyses. Generating integrated weather hazards maps will allow the model to predict the interaction of multiple natural hazards and, most importantly, analyse and assess risk. The expected improvement in resolution and the quality of generated forecasts will make even more reliable operational maps possible. Additionally, as the forecaster will be involved in the process of map control and will have to confirm the correctness of warning messages, the risk of misleading users will be significantly reduced.

Acknowledgments The article was prepared thanks to the ISOK project (IT System for Country's Protection against extreme hazards; POIG.07.01.00-00-025/09), which was financed by the European Fund of Regional Development under the Operational Programme Innovative Economy and the Polish Government.

Ethical standard The authors declare that there is no conflict of interests regarding the publication of this paper and that the research did not involve human participants and/or animals.

Open Access This article is distributed under the terms of the Creative Commons Attribution License which permits any use, distribution, and reproduction in any medium, provided the original author(s) and the source are credited.

\section{References}

Alfieri L, Salamon P, Pappenberger F, Wetterhall F, Thielen J (2012) Operational early warning systems for water-related hazards in Europe. Environ Sci Policy 21:35-49

Basher R (2006) Global early warning systems for natural hazards: systematic and people-centred. Philos Trans R Soc A 364:2167-2182 
Brönnimann S, Luterbacher J, Ewen T, Diaz HF, Stolarski RS, Neu U (ed) (2008) Climate variability and extremes during the past 100 years (advances in global change research 33). Springer Science + Business Media B.V.

Casati B, Wilson LJ, Stephenson DB, Nurmi P, Ghelli A, Pocernich M, Damrath U, Ebert E, Brown BG, Mason S (2008) Forecast verification: current status and future directions. Meteorol Appl 15:3-18

Dobesch H, Dumolard P, Dyras I (eds) (2007) Spatial interpolation for climate data: the use of GIS in climatology and meteorology. ISTE, London

Ebi KL, Schmier JK (2005) A stitch in time: improving public health early warning systems for extreme weather events. Epidemiol Rev 27:115-121

Elguindi N, Bi X, Giorgi F, Nagarajan B, Pal J, Solmon F, Rauscher S, Zakey A, Giuliani G (2011) Climatic model RegCM user manual-version 4.1. Trieste, Italy

Gaztelumendi S, Egaña J, Otxoa-de-Alda K, Hernandez R, Aranda J, Anitua P (2012) An overview of a regional meteorology warning system. Adv Sci Res 8:157-166. doi:10.5194/asr-8-157-2012

Golnaraghi M (ed) (2012) Institutional partnerships in multi-hazard early warning systems: a compilation of seven national good practices and guiding principles. Springer, Berlin

Guha-Sapir D, Below R, Hoyois P (2015) EM-DAT: international disaster database. Université Catholique de Louvain, Brussels, Belgium (www.emdat.be)

IPCC (2001) Climate Change 2001. Houghton JT, Ding Y, Griggs DJ, Noguer M, van der Linden PJ, Dai X, Maskell K, Johnson CA (eds) The scientific basis. Contribution of the Working Group I to the Third Assessment Report of the Intergovernmental Panel on Climate Change. Cambridge University Press, Cambridge

IPCC (2013) Climate Change 2013: The Physical Science Basis. IPCC Working Group I Contribution to Fifth Assessment Report of the Intergovernmental Panel on Climate Change. Cambridge University Press, Cambridge

Klein Tank AMG, Zwiers FW, Zhang X (2009) Guidelines on analysis of extremes in a changing climate in support of informed decisions for adaptation. Climate data and monitoring WCDMP-No 72, WMO-TD No 1500

Kundzewicz ZW (ed) (2012) Changes in flood risk in Europe. CRC Press, Boca Raton

Lakshmanan V, Smith T, Stumpf G, Hondl K (2007) The warning decision support system-integrated information. Weather Forecast 22:596-612

Lalaurette F (2003) Early detection of abnormal weather conditions using a probabilistic extreme forecast index. Q J R Meteorol Soc 129:3037-3057

Lendholt M, Hammitzsch M (2012) Towards an integrated information logistics for multi hazard early warning system. Open Environ Eng J 5:27-43

Mayhorn CB, McLaughlin AC (2014) Warning the world of extreme events: a global perspective on risk communication for natural and technological disaster. Saf Sci 61:43-50

Rogers D, Tsirkunov V (2011) Implementing hazard early warning systems. Report, Global Facility for Disaster Reduction and Recovery

Stanski HR, Wilson LJ, Burrows WR (1989) Survey of common verification methods in meteorology. World weather watch technical report no 8, WMO/TD No 358

Stensrud DJ, Wicker LJ, Xue M, Dawson DT II, Yussouf N, Wheatley DM, Thompson TE, Snook NA, Smith TM, Schenkman AD, Potvin CK, Mansell ER, Lei T, Kuhlman KM, Jung Y, Jones TA, Gao J, Coniglio MC, Brooks HE, Brewster KA (2013) Progress and challenges with Warn-on-Forecast. Atmos Res 123:2-16

Tang X, Feng L, Zou Y, Mu H (2012) The Shanghai multi-hazard early warning system: addressing the challenge of disaster risk reduction in an urban megalopolis. In: Golnaraghi M (ed) Institutional partnerships in multi-hazard early warning systems, chapter 7. Springer, Berlin, pp 159-179. doi:10. 1007/978-3-642-25373-7_7

Travis WR (2013) Design of a severe climate change early warning system. Weather Clim Extrem 2:31-38

UNISDR-United Nations International Strategy for Disaster Reduction) (2006) Developing early warning systems: a checklist. In: Proceedings of the third international conference on early warning

WMO (2005) Guidelines on integrating severe weather warnings into disaster risk management. WMO/TD No 1292

WMO (2010) Guidelines on early warning systems and application of nowcasting and warning operations. WMO/TD No 1559

WMO (2014) Disaster risk reduction work plan (2012-2015), 64th session of WMO executive council 25 June-3 July 2012, Geneva, Switzerland, 12 pp, updated as of 20 February 2014

Zillman JW (2003) Meteorological and hydrological early warning systems. In: Zschau J, Küppers A (eds) Early warning systems for natural disaster reduction. Springer, Berlin, pp 135-164 